P0139

\title{
TOP EFFICACY PERFORMERS: THE QUALITY TRADEOFFS IN LED LUMINAIRES
}

\author{
Naomi Miller \\ DOI 10.25039/x46.2019.PO139 \\ from \\ CIE x046:2019 \\ Proceedings \\ of the \\ 29th CIE SESSION \\ Washington D.C., USA, June 14 - 22, 2019 \\ (DOI 10.25039/x46.2019)
}

The paper has been presented at the 29th CIE Session, Washington D.C., USA, June 14-22, 2019. It has not been peer-reviewed by CIE.

(C) CIE 2019

All rights reserved. Unless otherwise specified, no part of this publication may be reproduced or utilized in any form or by any means, electronic or mechanical, including photocopying and microfilm, without permission in writing from CIE Central Bureau at the address below. Any mention of organizations or products does not imply endorsement by the CIE.

This paper is made available open access for individual use. However, in all other cases all rights are reserved unless explicit permission is sought from and given by the $\mathrm{CIE}$.

CIE Central Bureau

Babenbergerstrasse 9

A-1010 Vienna

Austria

Tel.: +43 17143187

e-mail: ciecb@cie.co.at

www.cie.co.at 


\title{
TOP EFFICACY PERFORMERS: THE QUALITY TRADEOFFS IN LED LUMINAIRES
}

\author{
Miller, N. J. \\ Pacific Northwest National Laboratory, Portland OR, USA \\ Naomi.Miller@pnnl.gov
}

DOI 10.25039/x46.2019.PO139

\begin{abstract}
In 2017, several luminaires in the LED Lighting Facts database claimed efficacies between 144 and $210 \mathrm{Im} / \mathrm{W}$. Samples were procured for testing and visual evaluation. Seven luminaire models were ordered, all but one having directly visible LED packages. They underwent photometric testing for comparison to manufacturer-claimed values. All but one performed between 150 and $200 \mathrm{~lm} / \mathrm{W}$. Pairs of each type were mocked-up in a lighting laboratory. Direct measurements of the exposed LEDs revealed luminances ranging from 626.000 to 1.150 .000 $\mathrm{cd} / \mathrm{m}^{2}$, with one employing diffusers at $41.500 \mathrm{~cd} / \mathrm{m}^{2}$.

23 lighting-experienced observers evaluated the luminaires, providing comments and an overall perceived dollar value. Only two luminaires received positive ratings of visual comfort and overall quality, those with either diffusers or reflector optics to reduce direct view of bare LEDs. The three rated highest for monetary value received positive comments in light distribution, colour, and visual comfort; the three lowest rated received the most negative glare comments. The highest rated luminaire exhibited the lowest efficacy of $136 \mathrm{Im} / \mathrm{W}$, suggesting that visual comfort, light distribution, and colour quality may be of equal or greater importance to an installation.
\end{abstract}

Keywords: High-efficacy luminaires, lighting quality, visual comfort, glare metrics, LED luminance, laboratory testing, installation, observation, survey content analysis.

\section{Introduction}

For the design professional, selecting LED luminaires is a challenging task. The luminaire must deliver light where needed, while providing a range of lighting characteristics such as colour quality, minimal flicker, and visual comfort. LED products posed a dramatic departure from earlier lighting technologies, and one of several databases developed to highlight product quality issues and discourage low-quality products and inflated manufacturer claims was LED Lighting Facts, supported by the U.S. Department of Energy (DOE) from 2010 until 2018. This searchable listing exceeded 70.000 LED products, and was a means to narrow down the highest-performing lighting systems. Populated with families of lighting products, many of these were listed under the performance characteristics of the best individual product in the family. In 2017, some listed products surpassed $200 \mathrm{Im} / \mathrm{W}$ (DOE 2017) an achievement that represented a significant milestone in the development of solid-state lighting (SSL) luminaires. Because the database was used to assess the progress of the SSL industry, and used by specifiers for choosing products, the goal of this analysis was to examine whether the listed luminaires actually performed to the claimed efficacy level claimed, and what features or characteristics were consistent among those top performers.

The basis of this study was to anonymously purchase these top-efficacy luminaires, then conduct laboratory testing for a variety of performance measures. Then, the luminaires were installed in a mockup ceiling at a lab space, so that observers with a background in energy efficient lighting or energy management in facilities could visually evaluate the products for quality issues that are more difficult to quantify using conventional metrics.

This project was intended as a product evaluation and not a controlled scientific study with defined independent variables. 


\subsection{Background}

Several programs in the US have explored new lighting technologies and their implementation by testing lamps and luminaires purchased in the architectural lighting market. The DOE's CALiPER program was established in 2006 to use laboratory methods to test residential and commercial LED lamps and luminaires against manufacturer claims. It helped bring about more accurate performance reporting and identified quality issues such as colour characteristics and consistency that needed technological improvement, improved testing methods, or improved metrics.

Some studies have extended the evaluation work to installing the luminaires in a mockup environment, to take field measurements and bring in observers to provide evaluations of characteristics difficult to assess in the laboratory or missing reliable metrics to characterize behavior; issues such a flicker (CIE 2017), glare (Boyce 2014), dimming quality, and visual appearance. (Miller, 2013). This study continues in this tradition.

Glare is a particularly stubborn issue to quantify. Multiple metrics have been proposed over the decades, but none of them are reliable for evaluating potential glare from luminaires with uneven luminance distributions across the aperture. (Scheir, 2015) Metrics such as the Unified Glare Rating (UGR) assume that the luminance is uniform, or nearly so. UGR (CIE 1995) was a metric developed to unify several separately-developed glare metrics, and takes the following form for calculating a glare rating for either a specific room and layout of luminaires, or an individual luminaire:

$$
\mathrm{UGR}=8 \log _{10}\left(\frac{0.25}{L_{b}}\right) \sum\left(\frac{L_{s}^{2} * \omega}{p^{2}}\right)
$$

where

$L_{b}$ is the background luminance at the eye, excluding the contribution of the glare source $\left(\mathrm{cd} / \mathrm{m}^{2}\right)$

$L_{s}$ is the luminance of the glare source $\left(\mathrm{cd} / \mathrm{m}^{2}\right)$

$\omega$ is the solid angle of the glare source at the observer's eye, in steradians

$p$ is the Guth position index of the glare source

This calculation method offers no provision for evaluating glare responses from luminaires employing arrays of discrete LED packages, an optical design that has become common for industrial lighting, street and area lighting, and even some troffers and downlights.

\subsection{Methods}

\subsubsection{Luminaire selection}

The initial investigation into the highest-efficacy products listed by LED Lighting Facts began in January 2017, with the following approach:

Five products from the LED Lighting Facts database exceeding $140 \mathrm{Im} / \mathrm{W}$ were identified and procured, supplemented with two other known high-efficacy products identified through a web search. Three samples of each were purchased. Ordered products were configured as closely as possible to the highest-performing products listed in the database, within a range of 15.000 to 22.000 lumens, suitable for mounting in an industrial setting with a ceiling height of approximately $4,6 \mathrm{~m}$. The target lumen output was intended to duplicate the light output of a four-lamp T5HO 1,2 m fluorescent low-bay industrial luminaire, expected to produce about 18.000 lumens when new. Minimum acceptable reported CIE $R_{\mathrm{a}}(\mathrm{CRI})$ was 70.

All products exhibited correlated colour temperatures (CCTs) around $5000 \mathrm{~K}$. This is no surprise because higher-CCT phosphor-converted blue LED chips are higher in efficacy than warmer CCTs (all else equal); greater Stokes losses are incurred using more phosphors to downconvert to the warmer wavelengths needed to produce $4000 \mathrm{~K}$ and $3000 \mathrm{~K}$ spectra (Setlur, 2009).

All were described as suitable for industrial applications, with most exhibiting exposed LED packages or LED packages through clear glass or acrylic covers. One luminaire had linear 
diffusers over the rows of LED packages and shallow linear baffles between the diffusers; another used deeper linear baffles for high-angle glare control.

Figure 1 - The evaluated luminaires.

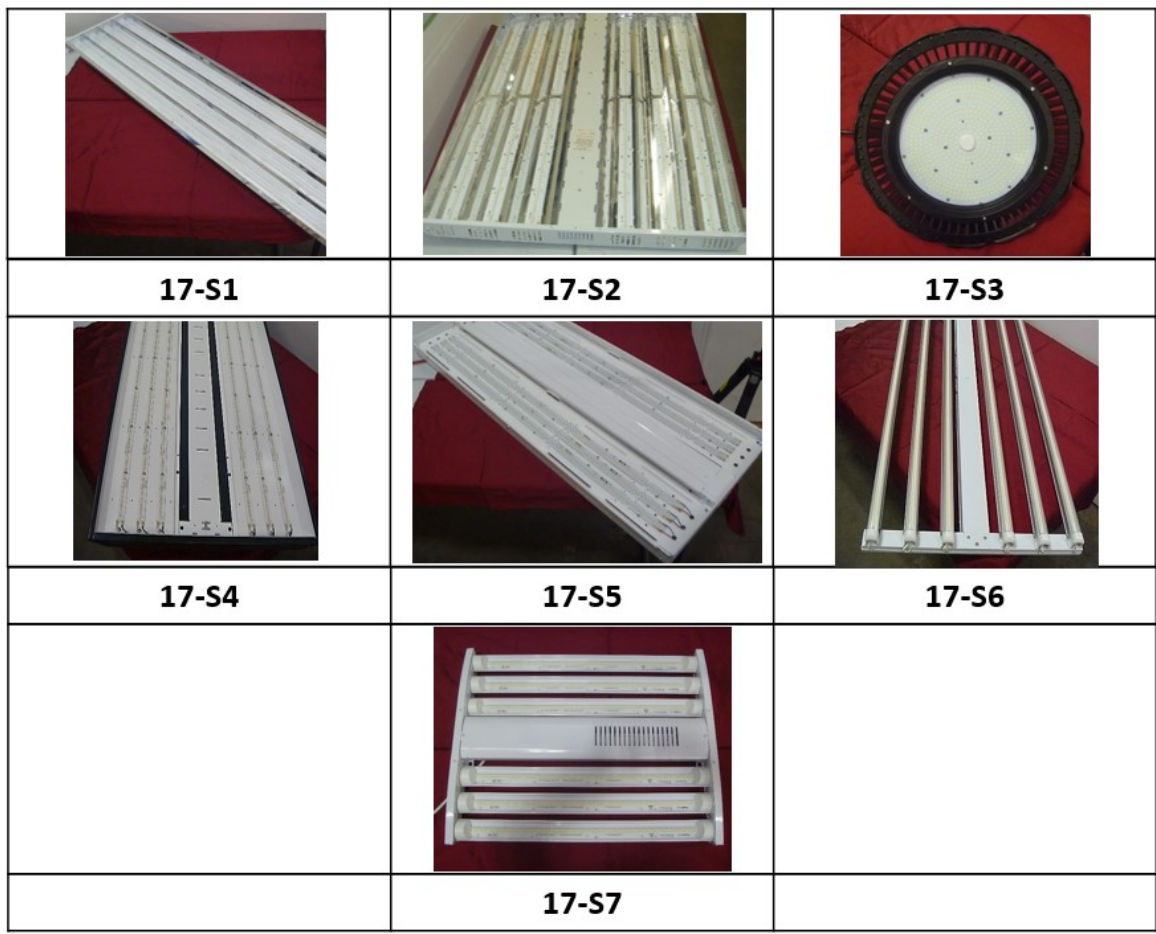

Figure 1 shows the seven luminaire types ordered in August 2017. Table 1 shows the performance values according to the manufacturers' online specification sheets. The last column shows the efficacy value from the LED Lighting Facts database.

Table 1 - Reported luminaire performance characteristics.

\begin{tabular}{|c|c|c|c|c|c|c|}
\hline System ID & $\begin{array}{c}\text { Manu- } \\
\text { facturer } \\
\text { Reported } \\
\text { Lumens }\end{array}$ & $\begin{array}{c}\text { Manu- } \\
\text { facturer } \\
\text { Reported } \\
\text { CCT }\end{array}$ & $\begin{array}{c}\text { Manu- } \\
\text { facturer } \\
\text { Reported } \\
\text { CRI }\end{array}$ & $\begin{array}{c}\text { Manu- } \\
\text { facturer } \\
\text { Reported } \\
\text { Wattage }\end{array}$ & $\begin{array}{c}\text { Manufacturer } \\
\text { Reported } \\
\text { Efficacy }\end{array}$ & $\begin{array}{c}\text { LED } \\
\text { Lighting } \\
\text { Facts } \\
\text { Listed } \\
\text { Efficacy }\end{array}$ \\
\hline $17-\mathrm{S} 1$ & 18.727 & 5000 & $\mathrm{n} / \mathrm{a}$ & 130 & 144 & 144,1 \\
\hline $17-\mathrm{S} 2$ & 19.464 & 5000 & $\mathrm{n} / \mathrm{a}$ & 118 & 165 & 164,5 \\
\hline $17-\mathrm{S} 3$ & 15.000 & 5000 & $>70$ & 100 & 150 & 175,5 \\
\hline $17-\mathrm{S} 4$ & 22.610 & 5000 & 77 & 106 & 213 & 209,7 \\
\hline $17-\mathrm{S} 5$ & 18.835 & 5000 & $>80$ & 115 & 164 & Not listed \\
\hline $17-\mathrm{S} 6$ & 22.671 & 5000 & 83 & 140 & 162 & 155,0 \\
\hline $17-\mathrm{S} 7$ & 18.000 & 5000 & 70 & 102 & 176 & Not listed \\
\hline
\end{tabular}

\subsubsection{Photometric testing}

Two samples of each luminaire model were photometrically tested, the third being tested only if there was more than a $10 \%$ discrepancy between the first two samples. Each luminaire was tested in an integrating sphere located in the PNNL NVLAP-accredited lighting metrology lab. Data were collected according to the IES LM-79-08 (IES 2008) method, and included electrical characteristics, light output, and spectral power distribution, all collected at full output. Measured values were compared to manufacturers' reported values, and those in the database. 


\subsubsection{Mockup installation}

Pairs of luminaires were installed in a lighting mockup environment featuring a $5,5 \times 5,5 \mathrm{~m}$ movable ceiling. (Figure 2) The ceiling was set to the maximum possible height, which was limited to 3,4 m above the floor due to mounting complications, lower than the 4,6 m anticipated. Each pair of luminaires was spaced $4,3 \mathrm{~m}$ on center, except for the 17-S2 luminaires, which were too large to be partially recessed in the T-bar ceiling grid, so they were installed instead at $4,1 \mathrm{~m}$ on center, shown in Figure 3 . Each luminaire pair was controlled by a separate toggle wall switch. Typical industrial assembly tasks were located on a movable table below the ceiling.

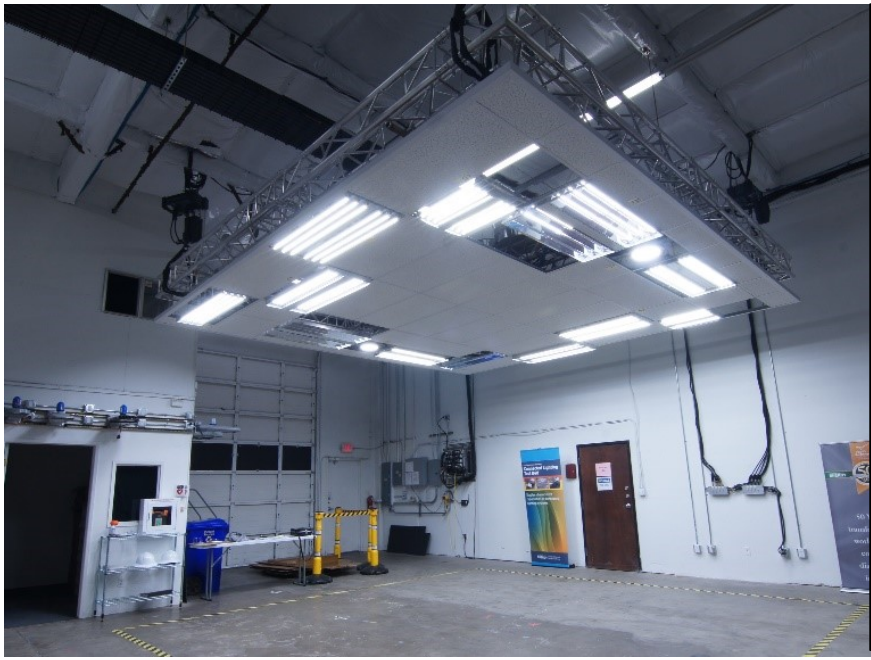

Figure 2 - Mockup space with all seven pairs of high efficacy performer luminaires installed and energized

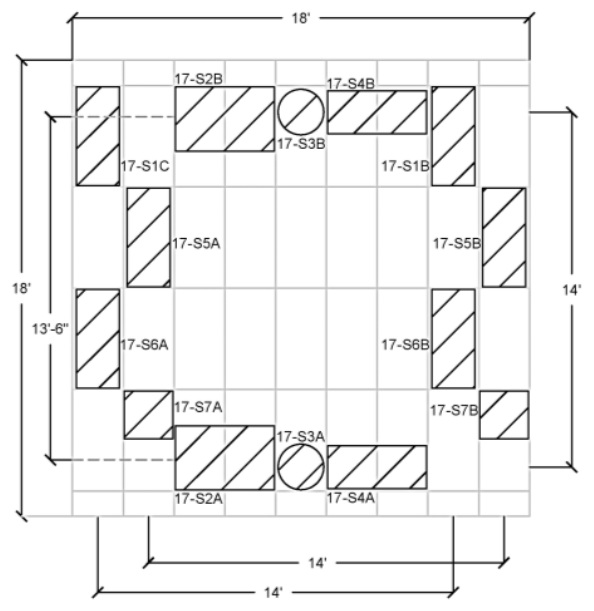

Figure 3 - Layout of luminaires in a movable ceiling within laboratory mockup space, labeled with their system IDs.

Daylight was blocked, but fluorescent striplights (F32T8/841 lamps, measured at $4528 \mathrm{~K}$ and $R_{a}$ of 79 ) provided ambient lighting above and around the movable ceiling space during the observations, to mimic light contribution from perimeter areas in actual industrial spaces. Ambient light, averaging $94 \mathrm{Ix}$ horizontal at the workplane and $105 \mathrm{Ix}$ at the floor, was subtracted from all reported illuminance measurements.

The following measurements were collected in the mockup space:

- Horizontal illuminance at the floor and at a $0.9 \mathrm{~m}$ high movable cart height (simulating a stand-up industrial task surface), at a line of points between pairs of luminaires. A Konica Minolta T-10A illuminance meter within calibration was used.

- Luminance measurements of the luminaire collected from nadir. The intent was to capture either the luminance of the diffuser covering the rows of LED packages or a direct measure of the luminance of the LED package itself. A Konica Minolta LS $-1601 / 3^{\circ}$ meter, within calibration was used, with close-up lenses to isolate the LED package in the meter's capture angle as much as possible.

\subsubsection{Observers and form for completion}

Twenty-three energy specialists, lighting specifiers, and facility managers were invited to the mockup space in February 2018 to experience and evaluate the installed industrial luminaires, one illuminated pair at a time. Individuals with sales occupations that could potentially bias their judgment were excluded. A form (Appendix 1) was provided to capture observations, including quality of the light in terms of colour, shadows, light distribution, visual comfort, appearance, and functionality. [Flicker was included but not addressed in this report.] Observers were also asked to assign an overall quality value for each luminaire by estimating how much they would pay for the luminaire, relative to a hypothetical benchmark price.

Groups of up to four individuals were scheduled for different time slots over three days, allowing the groups to see the luminaires presented in random order. Participants were given a set of 
verbal instructions and presented with clipboard materials which also served to permit the $m$ to adapt to the ambient light in the space, over a period of five to ten minutes. Observer instructions were delivered before the mockup luminaires were switched on. Care was taken not to prejudice the observers on what they were about to observe or influence any opinions about the luminaires' appearance or performance, and they were asked not to talk among themselves. The luminaire pairs were presented, one at a time, for about three minutes, with about a minute of off time between presentations, so that observers were not immediately able to compare the performance of a pair with the previously presented pair. The presentation order was randomized, with a unique first and last luminaire for each of the seven groups in order to minimize order effects. There was no identifying information on the luminaires, which were labeled A through $\mathrm{G}$.

The response form suggested several topic areas for comment [visual comfort, spread of light on the table top (that is, light distribution), shadows, colour quality, appearance, and functionality]. Observers were also asked to provide an overall quality measure by choosing how much they would pay for the luminaire, if the average price were $\$ 200$ for that genre of luminaire, purchased in quantities of 100 . This was presented not as a pricing exercise, but a way to estimate perceived value relative to an average price. From this, it was possible to estimate if the luminaire was perceived to be worth $50 \%$ more or $50 \%$ less than a typical luminaire, for example. After viewing all luminaires and completing the response forms, observers were invited to share their comments in a collective, informal debriefing session.

\section{Results}

\subsection{Laboratory testing results}

The laboratory tested performance values are summarized in Table 2, with the percentage differences from the manufacturer specification sheet data shown in parentheses. CCT colour performance varied by no more than $4,4 \%$ from reported values. A comparison of measured versus reported CRI values was not possible because some manufacturers reported no CRI values, or less specific ranges such as " $>70$." Of those reporting CRI values, only one tested lower than reported, by 1 point.

Table 2 - Laboratory tested performance values. Percent difference between lab tested values compared to manufacturer reported values (from website specification sheets) is shown in parentheses.

\begin{tabular}{|c|c|c|c|c|c|c|}
\hline System ID & $\begin{array}{c}\text { Lab Tested } \\
\text { CRI }\end{array}$ & $\begin{array}{c}\text { Lab Tested } \\
\text { Power (W) }\end{array}$ & $\begin{array}{c}\text { Lab Tested } \\
\text { Power Factor }\end{array}$ & $\begin{array}{c}\text { Lab Tested } \\
\text { Output (Im) }\end{array}$ & $\begin{array}{c}\text { Lab Tested } \\
\text { CCT (K) }\end{array}$ & $\begin{array}{c}\text { Lab Tested } \\
\text { Efficacy (Im/W) }\end{array}$ \\
\hline 17-S1B & 85 & $123,9(-4,7 \%)$ & 1,00 & $16.925(-9,6 \%)$ & $5.143(2,9 \%)$ & $136,6(-5,2 \%)$ \\
\hline $17-S 1 C$ & 84 & $124,9(-3,9 \%)$ & 1,00 & $17.018(-9,1 \%)$ & $5.115(2,3 \%)$ & $136,3(-5,4 \%)$ \\
\hline $17-S 2 A$ & 83 & $113(-4,2 \%)$ & 1,00 & $18.883(-3,0 \%)$ & $5.022(0,4 \%)$ & $167,1(1,3 \%)$ \\
\hline $17-S 2 B$ & 83 & $112,9(-4,3 \%)$ & 1,00 & $18.617(-4,4 \%)$ & $5.032(0,6 \%)$ & $164,9(0,0 \%)$ \\
\hline $17-S 3 A$ & 79 & $95,8(-4,2 \%)$ & 0,99 & $16.091(7,3 \%)$ & $5.218(4,4 \%)$ & $168(12,0 \%)$ \\
\hline $17-S 3 B$ & 79 & $98,2(-1,8 \%)$ & 0,99 & $16.234(8,2 \%)$ & $5.220(4,4 \%)$ & $165,3(10,2 \%)$ \\
\hline $17-S 4 A$ & 77 & $106,9(0,8 \%)$ & 0,99 & $21.336(-5,6 \%)$ & $4.895(-2,1 \%)$ & $199,6(-6,4 \%)$ \\
\hline $17-S 4 B$ & 77 & $107,3(1,2 \%)$ & 0,99 & $21.178(-6,3 \%)$ & $4.894(-2,1 \%)$ & $197,4(-7,5 \%)$ \\
\hline $17-S 5 A$ & 83 & $107,6(-6,4 \%)$ & 0,99 & $17.412(-7,6 \%)$ & $4.986(-0,3 \%)$ & $161,8(-1,2 \%)$ \\
\hline $17-S 5 B$ & 83 & $107,2(-6,8 \%)$ & 0,99 & $17.431(-7,5 \%)$ & $4.995(-0,1 \%)$ & $162,6(-0,7 \%)$ \\
\hline $17-S 6 A$ & 82 & $138(-1,4 \%)$ & 0,98 & $21.975(-3,1 \%)$ & $4.951(-1,0 \%)$ & $159,2(-1,7 \%)$ \\
\hline $17-S 6 B$ & 82 & $138,2(-1,3 \%)$ & 0,98 & $21.502(-5,2 \%)$ & $4.970(-0,6 \%)$ & $155,6(-3,9 \%)$ \\
\hline $17-S 7 A$ & 74 & $101,7(-0,3 \%)$ & 1,00 & $17.729(-1,5 \%)$ & $5.062(1,2 \%)$ & $174,3(-1,2 \%)$ \\
\hline $17-S 7 B$ & 74 & $101,1(-0,9 \%)$ & 1,00 & $18.127(0,7 \%)$ & $5.058(1.2 \%)$ & $179,3(1,6 \%)$ \\
\hline
\end{tabular}


Lumen output values were no more than $9,6 \%$ above or below the manufacturer reported values, and the power draw varied by as much as $6,8 \%$ from the reported values. Efficacies $(\mathrm{Im} / \mathrm{W})$ varied by as much as $12,0 \%$ from claimed values, although the tested efficacy values often were lower than expected, given the LED Lighting Facts listing based on top performers in a product family. Power factors were all above $90 \%$.

\subsubsection{Field testing results - Glare}

Glare metrics such as the Unified Glare Rating (UGR) assume that the luminance is uniform, and six of seven luminaire types installed for the mockup are extreme examples of nonuniformity because the individual LEDs are directly visible. One of the seven luminaire types (17-S1) used a white diffuser to obscure the view of the individual LEDs and spread the luminance over a larger surface area, and this was judged by observers to be far less glaring (see Section 3.3).

UGR was calculated for all seven luminaire types (Appendix 2). This required assumptions of viewing conditions and approximations of some values. The data needed for calculating a single-luminaire UGR value are: $L_{b}$ (background illuminance at the eye, excluding direct light from the luminaire), $L_{s}$ (source luminance from the observer's eye), $\omega$ (projected solid angle of the luminous area at the observer's eye), and $p$ (position index calculated per Figure 4.2 of CIE 1995). The geometry assumed for the UGR calculation is shown in Figure 3.

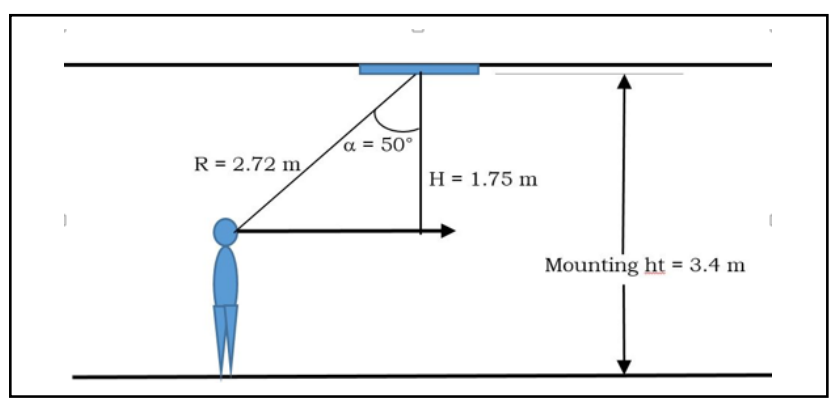

Figure 4 - Geometry of observer and luminaire used in UGR calculation.

Of the seven luminaire types, only two manufacturers made intensity distribution (that is, .ies) files available, so the light distribution was assumed to be Lambertian and the source luminance calculated from the average tested luminaire lumens for each luminaire type as shown in Table 2 , using the equation $L_{s}=$ Luminaire lumens $/ \pi{ }^{*}$ luminous area. (Although no goniophotometer laboratory testing was performed, the researchers estimated that only luminaire 17-S2 would have varied significantly from a Lambertian distribution, since it had reflectors to redirect light emitted at $75^{\circ}$ and above, in the cross-wise direction.)

Luminous area was assumed to be the aperture area of the luminaire as documented in the ies file, following North American photometry standards (IES 2002). Where no .ies file existed, the aperture dimensions were hand-measured and area calculated for a projected angle of $50^{\circ}$ from luminaire nadir. The background luminance was estimated at 500 lux at the eye, or $159 \mathrm{~cd} / \mathrm{m}^{2}$, for all luminaires.

The scale for UGR values ranges roughly from 10 to $30 \quad(<19$ is Acceptable, $>22$ is Unacceptable, $>25$ is Just Uncomfortable, $>28$ is Uncomfortable), and the calculated values for the seven studied luminaires range from "Acceptable" to "Uncomfortable." (Their rank order is shown in the final row of Appendix 2, but those rankings do not correspond to the observer ratings (see Section 2.1.4), likely because the luminaire aperture alone cannot characterize the non-uniform luminance distribution produced by visible LED packages, since the effective luminous area is far smaller. 
Table 3 - Measured luminances of individual LED packages or diffuser in luminaires.

\begin{tabular}{|c|c|c|c|c|c|c|c|c|}
\hline $\begin{array}{c}\text { System } \\
\text { ID }\end{array}$ & $\begin{array}{c}\text { Area } \\
\text { measured }\end{array}$ & $\begin{array}{l}\text { Avg. LED } \\
\text { package } \\
\text { or lens } \\
\text { luminance } \\
\text { (cd/m2) }\end{array}$ & $\begin{array}{c}\text { LED } \\
\text { package } \\
\text { width } \\
\text { (mm) }\end{array}$ & $\begin{array}{l}\text { LED } \\
\text { package } \\
\text { length } \\
(\mathrm{mm})\end{array}$ & $\begin{array}{c}\text { No. of } \\
\text { LED } \\
\text { packages } \\
\text { or } \\
\text { diffusers }\end{array}$ & $\begin{array}{l}\text { Lumi- } \\
\text { nous } \\
\text { area } \\
\left(\mathrm{m}^{2}\right)\end{array}$ & $\begin{array}{l}\text { Avg. } \\
\text { lumi- } \\
\text { naire } \\
\text { lumens }\end{array}$ & $\begin{array}{c}\text { Avg. } \\
\text { lumens } \\
\text { per } \\
\text { luminous } \\
\text { area } \\
\left({\left.\mathrm{Im} / \mathrm{m}^{2}\right)}^{2}\right.\end{array}$ \\
\hline 17-S1B & \begin{tabular}{|l} 
LEDs behind \\
diffuse \\
tubular cover
\end{tabular} & 41.523 & 20,0 & 1100,0 & 4 & 0,0880 & 16.972 & 192.864 \\
\hline $17-S 2 A$ & Bare LED & 661.024 & 3,0 & 3,0 & 1.080 & 0,0097 & 18.750 & 1.929 .012 \\
\hline $17-S 3 A$ & $\begin{array}{c}\text { Bare LED } \\
\text { behind clear } \\
\text { cover glass }\end{array}$ & 767.160 & 3,0 & 3,0 & 536 & 0,0048 & 16.163 & 3.350 .539 \\
\hline $17-S 4 A$ & Bare LED & 1.150 .543 & 3,0 & 3,0 & 756 & 0,0068 & 21.257 & 3.124 .192 \\
\hline 17-S5A & Bare LED & 1.069 .857 & 2,5 & 3,0 & 672 & 0,0050 & 17.422 & 3.456 .746 \\
\hline $17-S 6 A$ & \begin{tabular}{|l|} 
Bare LED, \\
behind clear \\
acrylic cover
\end{tabular} & 625.695 & 2,5 & 3,0 & 2.862 & 0,0215 & 21.975 & 1.023 .760 \\
\hline $17-S 7 A$ & Bare LED & 1.066 .823 & 2,0 & 4,0 & 576 & 0,0046 & 17.928 & 3.890 .625 \\
\hline
\end{tabular}

In order to better characterize the luminance distribution of the luminaires, LED package luminances were measured. These are listed in Table 3 along with the count of LED packages per luminaire. The luminances range from $41.500 \mathrm{~cd} / \mathrm{m}^{2}$ for Luminaire $17-\mathrm{S} 1$, which employed a $20 \mathrm{~mm}$ diameter by $1200 \mathrm{~mm}$ long diffuser over each row of LED packages, up to 1.150 .000 $\mathrm{cd} / \mathrm{m}^{2}$ for Luminaire 17-S4 which exhibited exposed LED packages. Compare these values to the luminance of a comparable lamp technology used in industrial applications, that of bare T5HO fluorescent lamps of $25.000-30.000 \mathrm{~cd} / \mathrm{m}^{2}$.

\subsubsection{Field testing results - Illuminance distribution on floor and workplane}

Horizontal illuminance was measured under each pair of test luminaires to evaluate lighting uniformity on the floor and work plane, subtracting ambient illuminance from the results. Illuminances varied for each luminaire type, from an average of 514 to $774 \mathrm{Ix}$ at the floor with a maximum-to-minimum uniformity no greater than 1,3 ; at the $0,9 \mathrm{~m}$ workplane height, the average ranged from 811 to $1.081 \mathrm{Ix}$, with a maximum-to-minimum uniformity no greater than 1,7. These bracket the range of $1000 \mathrm{Ix}$ recommended in the IES Lighting Handbook $\left(10^{\text {th }}\right.$ Edition) for difficult industrial assembly tasks. Luminaires 17-S1 and 17-S2 both featured linear baffles that controlled glare to some extent (the baffles for 17-S2 were deeper than those for 17-S1), and these luminaires produced slightly higher maximum-to-minimum illuminance uniformity ratios between luminaires.

\subsubsection{Visual evaluation results}

The anonymized, completed forms were processed and analyzed following a Content Analysis procedure described in Gifford 2016. Two researchers unassociated with the experimental design analyzed written comments from each participant, evaluating the theme of the comment and its valence, i.e., whether it was positive, neutral, or negative. Each theme and valence was counted for frequency and reported as a percentage of the total comments for that luminaire. For example, "Excellent visual comfort/appearance; Minimal Shadowing; Great illumination; Nice colour rendition; Good coverage on table" was translated as positive for the topics of light distribution, colour, shadowing, appearance, and visual comfort. "Very even, soft shadows on floor; Bright source, kinda glary; Colour rendition adequate; Table evenly illuminated; Double shadows when writing from hand" was translated as positive for light distribution, neutral for colour, and negative for visual comfort and shadows. Some positive comments were relative to luminaires previously viewed, especially for the issue of visual comfort. For example, an observer may have written that the "glare is less awful than observed from the previous luminaire." For this reason, counts of negative responses were found to be more reliable than counts of positive comments. Unaddressed issues received no positive, neutral or negative count. 
The participant responses were tallied, although not all participants addressed every issue. Table 4 shows the percentage of negative comments for all issues overall, followed by the three most dominant issues: visual comfort, distribution, and colour. They are listed by rank order, that is, the luminaire with the least percentage of negative comments is ranked \#1, and the luminaire with the highest percentage of negative comments is ranked \#7. The rank orders based on overall comments, colour, and visual comfort are very similar. Only luminaires 17-S6 and 17-S7 switch rank position between the columns of overall comments and colour; only luminaires 17-S3 and 17-S7 switch rank position between the columns of overall comments and visual comfort. This suggests that colour and visual comfort weighed heavily in the observers' comments on quality issues. (Interestingly, the ranking of colour does not closely correspond to $R_{\mathrm{a}}(\mathrm{CRI})$ measurements for the luminaires, found in Table 2.)

Observers offered the most consistently critical responses regarding visual comfort. $17,9 \%$ (or 161) of all comments (897) received across luminaires referenced visual comfort, reflected by the comparatively high percentage of negative responses shown in the visual comfort column. (Table 4)

Table 4 - Observer survey results. Percentage responses of negative comments for each luminaire based on ranking for overall comments, visual comfort, distribution, and colour. Luminaires are ranked from highest (1) to lowest (7).

\begin{tabular}{|c|c|c|c|c|c|c|c|c|}
\hline \multirow{2}{*}{ Rank } & \multicolumn{2}{|c|}{$\begin{array}{c}\text { Overall } \\
\text { Comments }\end{array}$} & \multicolumn{2}{c|}{ Visual Comfort } & \multicolumn{2}{c|}{ Distribution } & \multicolumn{2}{c|}{ Colour } \\
\cline { 2 - 9 } & $\begin{array}{c}\text { System } \\
\text { ID }\end{array}$ & $\begin{array}{c}\% \\
\text { Neg. }\end{array}$ & $\begin{array}{c}\text { System } \\
\text { ID }\end{array}$ & $\begin{array}{c}\% \\
\text { Neg. }\end{array}$ & $\begin{array}{c}\text { System } \\
\text { ID }\end{array}$ & $\begin{array}{c}\% \\
\text { Neg. }\end{array}$ & $\begin{array}{c}\text { System } \\
\text { ID }\end{array}$ & $\begin{array}{c}\% \\
\text { Neg. }\end{array}$ \\
\hline 1 & $17-S 1$ & $6,8 \%$ & $17-S 1$ & $0,0 \%$ & $17-S 1$ & $5,7 \%$ & $17-S 1$ & $13,0 \%$ \\
\hline 2 & $17-S 2$ & $18,2 \%$ & $17-S 2$ & $27,8 \%$ & $17-S 6$ & $6,1 \%$ & $17-S 2$ & $14,3 \%$ \\
\hline 3 & $17-S 6$ & $25,4 \%$ & $17-S 7$ & $40,9 \%$ & $17-S 2$ & $14,8 \%$ & $17-S 6$ & $16,0 \%$ \\
\hline 4 & $17-S 7$ & $27,0 \%$ & $17-S 6$ & $53,6 \%$ & $17-S 3$ & $21,2 \%$ & $17-S 3$ & $22,7 \%$ \\
\hline 5 & $17-S 5$ & $35,3 \%$ & $17-S 5$ & $73,9 \%$ & $17-S 4$ & $24,2 \%$ & $17-S 5$ & $23,8 \%$ \\
\hline 6 & $17-S 3$ & $43,2 \%$ & $17-S 3$ & $84,6 \%$ & $17-S 5$ & $26,7 \%$ & $17-S 7$ & $32,0 \%$ \\
\hline 7 & $17-S 4$ & $44,7 \%$ & $17-S 4$ & $87,0 \%$ & $17-S 7$ & $36,4 \%$ & $17-S 4$ & $40,0 \%$ \\
\hline
\end{tabular}

There is not a direct relationship between the ranking order of luminaires for visual discomfort and the maximum luminances documented in Table 4, although the three luminaires with the three lowest measured luminances appear in the top four rankings. The 17-S1 luminaire with diffusers exhibited by far the lowest luminance, and received the top visual comfort ranking, with no negative comments from the observers.

In order to test UGR for predicting the discomfort glare response, the UGR values and their rank orders as calculated in Appendix 2, are listed in Table 6. These do not correspond to either the overall comments or the visual comfort comments rank orders previously discussed. Rather, the UGR rank ordering follows almost identically the order of the luminous aperture size, with the larger apertures calculating as more comfortable and smaller apertures as least. This suggests that UGR is not a robust predictor of glare from luminaires with non-uniform luminous apertures. 
Table 5 - Rank order of predicted glare of luminaires according to UGR calculations. See Appendix 2. Luminaires are ranked from highest (1) to lowest (7).

\begin{tabular}{|l|l|l|}
\hline \multirow{2}{*}{ Rank } & \multicolumn{2}{|l|}{$\begin{array}{l}\text { Predicted } \\
\text { Discomfort Glare } \\
\text { using UGR }\end{array}$} \\
\cline { 2 - 3 } & $\begin{array}{l}\text { System } \\
\text { ID }\end{array}$ & UGR \\
\hline 1 & $17-$ S2 & 18,6 \\
\hline 2 & $17-S 5$ & 18,9 \\
\hline 3 & $17-S 4$ & 20,7 \\
\hline 4 & $17-S 1$ & 20,9 \\
\hline 5 & $17-S 7$ & 23,8 \\
\hline 6 & $17-S 6$ & 24,9 \\
\hline 7 & $17-S 3$ & 27,0 \\
\hline
\end{tabular}

Table 6 - Ranking of luminaires based on perceived overall dollar value. Luminaires are ranked from highest (1) to lowest (7)

\begin{tabular}{|l|l|l|}
\hline \multirow{2}{*}{ Rank } & \multicolumn{2}{|l|}{$\begin{array}{l}\text { Overall } \\
\text { Value }\end{array}$} \\
\cline { 2 - 3 } & $\begin{array}{l}\text { System } \\
\text { ID }\end{array}$ & $\begin{array}{l}\text { Average } \\
\text { Value }\end{array}$ \\
\hline 1 & $17-$ S1 & $\$ 230$ \\
\hline 2 & $17-$ S2 & $\$ 196$ \\
\hline 3 & $17-$ S6 & $\$ 192$ \\
\hline 4 & $17-$ S7 & $\$ 191$ \\
\hline 5 & $17-S 5$ & $\$ 174$ \\
\hline 6 & $17-S 4$ & $\$ 173$ \\
\hline 7 & $17-S 3$ & $\$ 168$ \\
\hline
\end{tabular}

Table 6 shows the seven luminaire types ranked by the average dollar value the observers selected for each luminaire, if a typical product of that type cost $\$ 200$. Note that this value ranking of luminaires is almost identical to the ranking in Table 6 based on overall comments, with only 17-S3 and 17-S4 switching rank. Only 17-S1 was a product for which the average observer would pay more. 17-S1 was also the lowest efficacy product, demonstrating a possible tradeoff between visual comfort and efficacy among these low-bay industrial luminaires.

\section{Discussion}

\subsection{Limitations of product lists}

Product listings can be a useful resource for finding high-efficacy products. However, this should be an information-gathering step, not the only resource for selecting luminaires. It is necessary to go to the manufacturer's website for detailed information, since the product listing data may be based on the performance of a product very different from the one needed for a project. For example, among the seven luminaires procured and tested for this project, where manufacturer data on various options was available, the following were observed:

- Changing the CCT from $5000 \mathrm{~K}$ to $4000 \mathrm{~K}$ (within the product family) would result in up to a $13 \%$ drop in efficacy; changing from $5000 \mathrm{~K}$ to $3000 \mathrm{~K}$ would result in up to a $17 \%$ drop in efficacy.

- Changing the optical package from a cosine distribution (i.e., little optical control) to a narrower distribution suitable for taller ceiling heights or more focused task illumination would result in up to a $9 \%$ drop in efficacy. 
- Selecting a luminaire option that provides more protection from dust and dirt (such as one with a higher ingress protection rating), or a diffuser that obscures the view of the bare LEDs would result in up to a $16 \%$ reduction in efficacy.

Consequently, the efficacy value listed in the product database or listing for a particular product line may be higher than the actual efficacy of many configurations of that product. The listing should be used as a means to identify potential products, but not for specification.

\subsection{Photometric testing}

The seven luminaire pairs fared well overall when photometric test data was compared to manufacturer claimed values from their website product literature (not necessarily values listed in LED Lighting Facts). This suggests that manufacturers are focused on accurate reporting of performance data, perhaps because the product listing programs perform some policing of the listed data to reinforce data integrity.

\subsection{Feedback from observers}

Much was learned from the responses to the open survey forms. Observers principally used visual comfort, colour quality, and light distribution to make their principal judgments of the installed luminaires. The rank orders of overall comments, colour, and visual comfort corresponded very closely to the rank orders of average dollar value observers selected for each luminaire. Negative comments dominated the visual comfort responses, at roughly twice the percentage of those of other categories, except for luminaire 17-S1 that employed diffusers to spread the brightness of the LEDs over a larger area.

\subsection{Improved glare metrics are needed}

Laboratory testing plays a vital role in documenting lighting performance, and design professionals apply this information to produce more efficient lighted environments. However, less clearly measurable issues such as visual comfort may render high-efficacy luminaires less acceptable to building occupants. It is critical that the lighting industry develop predictive metrics in these areas; without them, specifiers cannot anticipate problems that could affect user comfort and product acceptability. This study demonstrates that very high efficacies are real, and perhaps some of that efficacy can be traded for improved visual comfort.

This work demonstrates the need for improved glare metrics and measurement techniques that consider luminance distribution. The average calculated aperture luminances ranged from 7500 to $98.000 \mathrm{~cd} / \mathrm{m}^{2}$, corresponding to UGR values categorized as ranging from acceptable to uncomfortable, but these UGR values did not correspond to the observer ratings of visual comfort. Direct measurements of maximum luminance ranged from $41.500 \mathrm{~cd} / \mathrm{m}^{2}$ for the luminaire with diffuser cover, to $1.150 .000 \mathrm{~cd} / \mathrm{m}^{2}$ for bare LED packages. Luminaires with the three lowest maximum luminance values received 3 out of 4 of the least negative ratings for visual comfort from observers, and the three highest dollar values. The ability to characterize the variation in luminance across the luminaire aperture, and a better estimate of size of the luminous area may improve the ability of UGR or other discomfort glare metrics to predict visual comfort.

\subsection{Limitations of this study}

Industrial luminaires in the 15.000 to 22.000 lumen range are often used with mounting heights of 3,7 to $6,1 \mathrm{~m}$ or even higher. This study's luminaires were mounted for observation only 3,4 $\mathrm{m}$ above the floor, and the average horizontal illuminances under and between pairs of luminaires were higher as a result, ranging from 811 to $1081 \mathrm{Ix}$. This lower-than-planned mounting height may have exaggerated the perceived glare for the observers, although it also raised the adaptation luminance.

The volunteer observers for this study were lighting-knowledgeable. All were familiar with industrial lighting products and could have made mental comparisons with lighting systems they have seen and experienced in their work. Although care was taken to reduce bias and order effects through the evaluation protocol, this was not a rigorously controlled human factors research study. However, it is often informative to get feedback from industry experts. 


\section{Conclusions}

In general, the LED luminaires performed very well in terms of efficacy and met expectations for colour quality in an industrial application. Efficacies ranged from 136 to $200 \mathrm{Im} / \mathrm{W}$, within $12 \%$ of their claimed efficacies. $R_{a}(\mathrm{CRI})$ and CCT were consistent with claimed values.

6 out of 7 of the selected luminaires exhibited bare LEDs, either exposed directly to view or mounted behind clear glass or acrylic. Spot luminance measurements of the very bright LEDs revealed luminances ranging from 626.000 to $1.150 .000 \mathrm{~cd} / \mathrm{m}^{2}$, which likely contributed to the strong glare response from observers, even though they were instructed not to examine the luminaire with more than a glance. The one luminaire with diffusion, with a comparatively low measured luminance of $41.500 \mathrm{~cd} / \mathrm{m}^{2}$, was deemed acceptable for an industrial space. (Compare that to a T5HO fluorescent lamp at approximately $25-30.000 \mathrm{~cd} / \mathrm{m}^{2}$.)

At this time there is no glare metric that takes the spatial variations in luminance into account, so current metrics are unable to distinguish between the luminance from a single tiny bright dot or a large diffuse area source if they both produce the same luminous intensity in a given direction and have the same aperture area. That may change in the near future, with increased focus on improving glare metrics. In the meantime, it is important to communicate that the view of bare, high-luminance LED packages may result in a heightened glare response, compared to luminaires with diffusers, lenses, or other optical techniques to spread the source luminance over a larger area.

An analysis of subjective open responses and post-observation discussions suggests that visual comfort/glare was a significant factor in the evaluation of product quality. The two luminaires that utilized simple optics to either diffuse high luminance or cut off view of the LEDs above a fixed viewing angle, received the highest rankings of product dollar value and overall comments on quality from the observers of the installation. The third-ranked luminaire used a large count of lower-luminance LEDs, which may have effectively spread the luminance over a larger luminous area.

Colour quality and light distribution also received high numbers of observer comments, with colour rankings corresponding more closely to overall comment rankings and dollar cost value. Colour rankings did not correspond to the rankings based on $R_{a}(\mathrm{CRI})$.

This report demonstrates that there are bonafide LED products that perform at very high levels of efficacy, ranging from 136 to $200 \mathrm{~lm} / \mathrm{W}$. LED Lighting Facts and similar databases can be an excellent source of information, but it is incumbent on the specifier to investigate the performance of the specific product needed. With due diligence, high-performing LED products are available for virtually all architectural applications, although there are inevitably tradeoffs to be made for comfort, colour, distribution, and other lighting quality issues. 


\section{Appendix 1. Questionnaire}

Top Efficacy Performers Questionnaire

\begin{tabular}{l} 
Profession: \begin{tabular}{|l|l|l|l|l|l|l|}
\hline Engineer & $\begin{array}{l}\text { Lighting } \\
\text { Designer }\end{array}$ & $\begin{array}{c}\text { Rep or } \\
\text { Agent }\end{array}$ & Architect & Facility Mgr & Contractor & Other \\
\hline
\end{tabular} \\
Years of experience in lighting and/or construction: \\
\hline
\end{tabular}

Group No.

Instructions: Pairs of industrial luminaires are mounted at 11'-3" above the floor. A table is located between the two, with a variety of objects you can use to simulate an assembly task. Take 3 minutes to walk around the tables and provide comments/observations on each type. Please do not share your thoughts with others, yet.

\begin{tabular}{|c|c|c|c|c|c|}
\hline & & \multirow[t]{2}{*}{$\begin{array}{l}\text { Written comments } \\
\text { Please provide comments on the luminaires, using your knowledge and experience. } \\
\text { Consider respond to the following issues: SPREAD OF LIGHT ON THE TABLE TOP, } \\
\text { SHADOWS, VISUAL COMFORT, COLOR QUALITY, APPEARANCE, FUNCTIONALITY, } \\
\text { ETC. }\end{array}$} & \multicolumn{2}{|c|}{$\begin{array}{c}\text { If this type of luminaire } \\
\text { costs } \$ 200 \text { on average, } \\
\text { what would you pay for } \\
\text { this one? }\end{array}$} & \multirow[t]{2}{*}{$\begin{array}{l}\text { Additional } \\
\text { comments? } \\
\text { Where would you } \\
\text { recommend this } \\
\text { product? }\end{array}$} \\
\hline \multirow{7}{*}{ 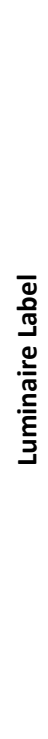 } & A & & $\begin{array}{l}\square \$ 100 \\
\square \$ 150 \\
\square \$ 200\end{array}$ & $\begin{array}{l}\square \$ 250 \\
\square \$ 300\end{array}$ & \\
\hline & B & & $\begin{array}{l}\square \$ 100 \\
\square \$ 150 \\
\square \$ 200\end{array}$ & $\begin{array}{l}\square \$ 250 \\
\square \$ 300\end{array}$ & \\
\hline & C & & $\begin{array}{l}\square \$ 100 \\
\square \$ 150 \\
\square \$ 200 \\
\end{array}$ & $\begin{array}{l}\square \$ 250 \\
\square \$ 300\end{array}$ & \\
\hline & D & & $\begin{array}{l}\square \$ 100 \\
\square \$ 150 \\
\square \$ 200\end{array}$ & $\begin{array}{l}\square \$ 250 \\
\square \$ 300\end{array}$ & \\
\hline & $E$ & & $\begin{array}{l}\square \$ 100 \\
\square \$ 150 \\
\square \$ 200 \\
\end{array}$ & $\begin{array}{l}\square \$ 250 \\
\square \$ 300\end{array}$ & \\
\hline & $F$ & & $\begin{array}{l}\square \$ 100 \\
\square \$ 150 \\
\square \$ 200\end{array}$ & $\begin{array}{l}\square \$ 250 \\
\square \$ 300\end{array}$ & \\
\hline & G & & $\begin{array}{l}\square \$ 100 \\
\square \$ 150 \\
\square \$ 200\end{array}$ & $\begin{array}{l}\square \$ 250 \\
\square \$ 300\end{array}$ & \\
\hline
\end{tabular}


Appendix 1 - UGR calculated for each of the luminaire types, using luminaire aperture as luminous area.

\begin{tabular}{|c|c|c|c|c|c|c|c|c|}
\hline Image & & & & & & & 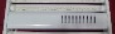 & Comments \\
\hline Description & $17-S 1$ & $17-S 2$ & $17-\mathrm{S} 3$ & $17-\mathrm{S} 4$ & $17-55$ & $17-56$ & $17-57$ & \\
\hline $\begin{array}{l}\text { Luminaire aperture size, } \\
\text { per photometric report, } \\
\mathrm{m}^{2} \text { (Luminaires marked } \\
\text { with * had no } \\
\text { photometric reports } \\
\text { available, so aperture } \\
\text { size was estimated) }\end{array}$ & $\begin{array}{c}0.2794 \mathrm{~m} \mathrm{x} \\
1.1938 \mathrm{~m} \\
\text { aperture * }\end{array}$ & $\begin{array}{c}0.6604 \mathrm{mx} \\
1.1938 \mathrm{~m} \\
\text { aperture * }\end{array}$ & $\begin{array}{c}0.258 \mathrm{~m} \text { dia } \\
\text { aperture * }\end{array}$ & $\begin{array}{l}1.1552 \mathrm{mx} \\
0.4816 \mathrm{~m} \\
\text { aperture }\end{array}$ & $\begin{array}{c}1.2192 \mathrm{mx} \\
0.5080 \mathrm{~m} \\
\text { aperture }\end{array}$ & $\begin{array}{c}0.025 \mathrm{~m} \times 6 \mathrm{x} \\
1.1938 \mathrm{~m} \\
\text { aperture * }\end{array}$ & $\begin{array}{c}0.2682 \mathrm{mx} \\
0.6096 \mathrm{~m} \\
\text { aperture * }\end{array}$ & \\
\hline Luminaire aperture area & 0.3335 & 0.7884 & 0.0523 & 0.5563 & 0.6194 & 0.1791 & 0.1635 & \\
\hline $\begin{array}{l}\text { Observer distance to the } \\
\text { luminaire, } r, m\end{array}$ & 2.72 & 2.72 & 2.72 & 2.72 & 2.72 & 2.72 & 2.72 & \\
\hline $\begin{array}{l}\text { Solid angle of aperture, } \\
\omega, \mathrm{sr}\end{array}$ & 0.028975 & 0.068498 & 0.004544 & 0.048332 & 0.053815 & 0.015561 & 0.014205 & \\
\hline Luminaire lumens & 16972 & 18750 & 16163 & 21257 & 17422 & 21975 & 17928 & \\
\hline $\begin{array}{l}\text { Average luminance of } \\
\text { the luminaire, assuming } \\
\text { Lambertian distribution, } \\
\mathrm{L}_{\mathrm{s}}, \mathrm{cd} / \mathrm{m}^{\wedge} \mathbf{2}\end{array}$ & 16199 & 7570 & 98372 & 12163 & 8953 & 39056 & 34903 & \\
\hline $\begin{array}{l}\text { Assumed background } \\
\text { luminance } L_{b}\left(c d / m^{\wedge} 2\right)\end{array}$ & 159 & 159 & 159 & 159 & 159 & 159 & 159 & $\begin{array}{l}\text { Estimated at } 500 \text { lux at the eye. Equation } 4.2 \\
\text { from } U G R, L(b)=E(i) / \pi\end{array}$ \\
\hline $\begin{array}{l}\text { Position index for } \\
\text { observer geometry, } p\end{array}$ & 5.4 & 5.4 & 5.4 & 5.4 & 5.4 & 5.4 & 5.4 & $\begin{array}{l}\text { Using Table } 4.1 \text { and Figure } 4.2 \text { from UGR } \\
\text { document. } \mathrm{H}=1.75 \mathrm{~m}, \mathrm{R}=2.09 \mathrm{~m}, \mathrm{~T}=0 \mathrm{~m}\end{array}$ \\
\hline $\begin{array}{l}\text { UGR value (source area } \\
\text { is full aperture window) }\end{array}$ & 20.9 & 18.6 & 27.0 & 20.7 & 18.9 & 24.9 & 23.8 & \\
\hline $\begin{array}{l}\text { Ranking from least (1) to } \\
\text { most (7) discomfort } \\
\text { glare according to } \\
\text { conventional UGR } \\
\text { calculation }\end{array}$ & 4 & 1 & 7 & 3 & 2 & 6 & 5 & \\
\hline
\end{tabular}

\section{References}

Boyce, PR. 2014. Human Factors in Lighting, $3^{\text {rd }}$ Edition. CRC Press, Taylor and Francis Group, LLC. Pp. 172-179.

[CIE] Commission Internationale de l'Eclairage TN 008:2017. Final Report CIE Stakeholder Workshop for Temporal Light Modulation Standards for Lighting Systems. Vienna.

[DOE] U.S. Department of Energy. 2017. CALiPER Snapshot on Industrial Luminaires. U.S. Department of Energy, Energy Efficiency and Renewable Energy, Building Technologies Office. PNNL-SA-125023 https://www.energy.gov/sites/prod/files/2017/04/f34/snapshot2017_industrial.pdf

Gifford, R, ed. 2015. Research Methods for Environmental Psychology, Chapter 13. John Wiley $\&$ Sons.

[IES] Illuminating Engineering Society LM-79-2008, Electrical and Photometric Measurements of Solid-State Lighting. New York.

[IES] Illuminating Engineering Society LM-63-2002, IESNA Standard file format for the electronic transfer of photometric data and related information. New York.

Miller NJ, Royer MP, Poplawski ME. 2013. CALiPER Exploratory Study: Recessed Troffer Lighting. U.S. Department of Energy, Office of Energy Efficiency \& Renewable Energy, Washington

https://www1.eere.energy.gov/buildings/publications/pdfs/ssl/caliper_recessedtroffer_2013.pdf

Scheir, GH and others, 2015. Calculation of the Unified Glare Rating based on luminance maps for uniform and non-uniform light sources. Building and Environment Vol. 84, pp. 60-67.

Setlur, AA. 2009. Phosphors for LED-based Solid-State Lighting. The Electrochemical Society Interface. https://www.electrochem.org/dl/interface/wtr/wtr09/wtr09_p032-036.pdf 